\title{
Researching Collaborative Advantage Some Conceptual and Multi-level Issues
}

\author{
Foss, Nicolai Juul; Nielsen, Bo Bernhard
}

Document Version

Final published version

Publication date:

2010

\section{License \\ CC BY-NC-ND}

Citation for published version (APA):

Foss, N. J., \& Nielsen, B. B. (2010). Researching Collaborative Advantage: Some Conceptual and Multi-level Issues. Center for Strategic Management and Globalization. SMG Working Paper No. 6/2010

Link to publication in CBS Research Portal

\section{General rights}

Copyright and moral rights for the publications made accessible in the public portal are retained by the authors and/or other copyright owners and it is a condition of accessing publications that users recognise and abide by the legal requirements associated with these rights.

Take down policy

If you believe that this document breaches copyright please contact us (research.lib@cbs.dk) providing details, and we will remove access to the work immediately and investigate your claim. 
Researching Collaborative Advantage:

Some Conceptual and Multi-level Issues

Nicolai J. Foss

Bo B. Nielsen

SMG WP 6/2010

August, 2010 
SMG Working Paper No. 6/2010

August, 2010

ISBN: 978-87-91815-59-1

Center for Strategic Management and Globalization Copenhagen Business School

Porcelænshaven 24

2000 Frederiksberg

Denmark

www.cbs.dk/smg 
RESEARCHING COLLABORATIVE ADVANTAGE: SOME CONCEPTUAL AND MULTI-LEVEL ISSUES

\author{
Nicolai J. Foss \\ Center for Strategic Management and Globalization \\ Copenhagen Business School \\ Porcelænshaven 24, $1^{\text {st }}$ fl.; 2000 Frederiksberg; Denmark \\ njf.smg@cbs.dk \\ Bo B. Nielsen \\ Center for Strategic Management and Globalization \\ Copenhagen Business School \\ Porcelænshaven 24, $1^{\text {st }}$ fl.; 2000 Frederiksberg; Denmark \\ University of Technology Sydney \\ bn.smg@cbs.dk
}

August, 2010

SMG Working Paper 


\section{INTRODUCTION}

As the editors of this volume note in their introductory chapter, collaboration is inherent in any operating market economy, and collaboration is, of course, sought because of the advantages it yields relative to non-collaboration. At the most abstract level, "collaboration" simply means "nonautarcic"; thus, Austrian economist Ludwig von Mises (1936) saw the division of labor as organized under capitalist institutions as a primary example of peaceful collaboration. Less abstractly, collaborative advantage may be related to notions of social capital and generalized trust. Still, such understandings capture a very large part of extant social science research. A more narrow understanding of collaborative advantage is required, lest we merely engage in an unproductive relabeling game. In fact, starting with important contributions by, for example, Hirschman (1970) and Richardson (1972), modern writers associate collaborative advantage with (typically) longlasting and stable relations between actors, supported by informal trust relations, relations based on formal contracts or property rights, or some combination thereof (Lazzarini, Miller \& Zenger, 2004). The relevant actors may exist at different analytical levels (e.g., individuals, firms, dyads, industries, clusters, regions, nations) and may in turn be embedded in various formal and informal institutions (North, 1990), as well as in certain geographical contexts.

However, even this conceptual narrowing of the notion of collaborative advantage still implies that we are making reference to very large and still expanding literatures in (fields in) economics (e.g., economic geography, urban economics, trade theory) and sociology, as well as management fields, such as strategic management, international business, and innovation studies. In various field and discipline-specific ways, these examine the morphology of collaboration and collaborative advantage, and seek to identify their antecedents and consequences. Methods differ, ranging from longitudinal single case studies to multi-level panel data studies using state of the art econometrics. Not surprisingly, it is far from clear that what is effectively a jumble of contributions 
actually adds up to robust generalizations and insights. Parts of extant work on collaboration and collaborative advantage is nicely summarized in the editors' introductory chapter.

In this chapter we argue that because there are so few obvious constraints on the meaning of collaboration on the social domain, and because it is mixed up with fundamental multi-level issues, both with respect to conceptualization, antecedents and consequences, clarity and rigor with respect to construct definition, location of constructs at various analytical levels, and methods is absolutely essential. For example, while collaborative advantage may be well-defined at the level of firm dyads (Richardson, 1972; Williamson, 1985; Dyer \& Wilkins, 1993), it may be (in fact, is) less well defined at higher levels of analysis, such as industries or industrial districts. Or, collaborative advantage at these latter levels may actually mean something different from collaborative advantage at the dyadic level, and have different antecedents and consequences. For example, as the notion of collaborative advantage traverses levels of analysis, antecedents likely differ (Nielsen, 2010).

As these examples suggest, many of the difficulties of researching collaboration and collaborative advantage stem from the multi-level nature of these constructs themselves, as well as from the fact that their antecedents and consequences may be located at multiple different levels. For instance, with respect to antecedents, dyad-level collaborative advantage (e.g., superior innovation resulting from pooling innovation capabilities in specific projects) may arise from particularly skilled R\&D personnel or alliance managers; the firms' endowments of innovation capabilities or their experiences from previous R\&D collaboration; advantages accruing to the specific region they are located in; governmental support programs; broad societal institutions; etc. Thus, collaborative advantage may have antecedents on lower ("micro") as well as higher ("macro") analytical levels (Knudsen \& Nielsen, 2010). In fact, one of our key points in the following is that researching collaborative advantage inherently requires a multi-level approach. Theoretically, account must be made of antecedents and consequences at different levels, as well as 
potential cross-level effects. In extant research, this is often not done; for example, research on national systems of innovation (e.g., Lundvall, 1992) often makes no reference to firms whatsoever (which logically must be part of the micro-foundations of such systems). By the same token, little effort has been devoted to defining the level at which constructs operate and little theory development within the strategic alliance field explicitly addresses the role played by variables at different levels (Nielsen, 2010). Proper-multilevel—empirical research methods must be adopted; otherwise, relevant causes are not identified and/or estimated parameters become biased.

Accordingly, this chapter offers a condensed primer on multi-level conceptual and methodological issues pertaining to collaborative advantage in order to guide future research. Rather than striving to be all-encompassing, we focus our discussion on a particular type of collaboration - strategic alliances among independent business firms - as this area of research continues to play a central role in strategic management, international business and organizational science. Despite this focus, most of the ensuing discussion applies equally well to other kinds of collaborations and we draw parallels to these where relevant. A further limitation is that we restrict our inquiry to variable-centered theoretical and empirical inquiry, and as such do not touch upon collaborative advantage in the context of small-N research, such as narrative approaches or approaches relying on comparative case method.

\section{COLLABORATIVE ADVANTAGE: MEANING}

\section{Construct Clarity}

Constructs are among the fundamental building blocks of theories, and clear constructs are necessary (if insufficient) for good theorizing. Thus, clear constructs make it easier to coordinate and disseminate research efforts because clarity facilitates communication. This promotes the growth of knowledge. Clarity also eases empirical work, by making it easier to identify proper 
sample frames, reducing concerns with construct validity, etc. As Suddaby (2010: 347) explains, there are four basic elements of arriving at clear constructs - namely,

1. providing definitions which involves "the skillful use of language to persuasively create precise and parsimonious categorical distinctions between concepts" (p.347);

2. identifying scope conditions that delineate the circumstances under which the concept meaningfully applies;

3. clarifying semantic relationships to other related constructs (as constructs do not arise de novo, but build on other, existing constructs); and, finally,

4. demonstrating the logical consistency or coherence of the construct in relation to the overall theoretical argument being made.

Constructs do not come ready made with clear definitions, properly delineated scope conditions, etc. While a significant part of scientific activity is establishing causal links between constructs (i.e., theorizing) and testing the resulting propositions, sorting out definitional issues, scope conditions, semantics, etc. issues constitute a quite significant and important part of scientific activity, not the least in the social sciences.

To illustrate with a highly relevant construct, "competitive advantage" has been around in the strategic management field, one of the major management fields, for at least four decades. It is conventionally taken to be the central construct of the field, and as such it is a construct that serves to organize research efforts in the field. For example, "strategies" are often conceptualized as plans regarding how to achieve competitive advantage. However, it remains a fact that it is only quite recently that this central, organizing construct has been properly clarified in terms of precise definitions and scope conditions (Peteraf \& Barney, 1993). ${ }^{1}$ For example, much strategic

\footnotetext{
${ }^{1}$ Given the huge success of the strategic management field, this suggests that fields can in fact flourish even in the presence of considerable conceptual ambiguity. Thus, conceptual clarity should not be taken as a necessary condition of scientific progress. However, the counterfactual argument may be made that had the strategic management field (as well as other fields and disciplines that have fuzzy concepts at the heart of their analytical enterprise) adopted clearer key
} 
management literature (still) discusses competitive advantage in terms of financial success (properly an outcome of competitive advantage) and conceptualizes it relative to suppliers and buyers (rather than only competitors). If a relatively established concept that has served to organize research efforts in an influential field for four decades can be fraught with lack of definitional and scope clarity, we should not be surprised to see more recent constructs also being characterized by lack of clarity, etc. We argue that this is, in fact, the case with collaborative advantage.

\section{Collaborative Advantage}

"Collaborative advantage" is clearly a recent construct. It appears that the construct was first coined in the beginning of the 1990s, specifically in Kanter's (1994) Harvard Business Review article, where she coins and uses the concept to refer to the specific advantages that may accrue to firms that set up strategic partnerships with other firms (e.g., joint ventures) by virtue of such cooperation. Another early inventor/adopter of the construct is Huxham (1996), who uses the construct generically to refer to any advantage to any kind of collaboration, apparently at any level of analysis (cf. also Huxham \& Vangen., 2005). ${ }^{2}$ Subsequently, the construct appears to have mainly been applied in the context of work on strategic alliances written for the popular business book market (e.g., Dyer, 2000; Lanter, 2005). Use of the Google Scholar search engine confirms that the construct does not enjoy widespread use in the academic journals, although it obviously connects to a very broad set of established social science and management constructs and ideas.

Given this context of the construct, it is, perhaps, not surprising that no rigorous definitions of the construct have been forwarded. Writers usually rest content with providing illustrative examples of collaborative advantage, examples that somehow suggest that partners to some venture may realize advantage that accrue to them by virtue of their specific collaboration. This is so broad as to

constructs earlier, it would have progressed even more. We submit that the same applies in the case of collaborative advantage.

${ }^{2}$ At any rate, using internet search tools, we have not been able to locate earlier uses of the construct. 
make the construct almost devoid of content, and illustrates what Suddaby (2010: 348) calls the "most common error in developing constructs ... making them too general."

Moreover, because of the potentially extreme inclusiveness of the collaborative advantage construct, it may seem hard to say anything meaningful about approaches to researching collaborative advantage, the main purpose of the present chapter. Thus, if collaborative advantage can, in principle, be applied to any level of analysis - that is, the dependent variable "collaborative advantage" can meaningfully be postulated at any level ranging from the level of collaborating individuals to collaborating nations_- basic problems regarding the nature of the explanans (i.e., the independent variables and how they are causally related) emerge: It is highly unlikely that the theoretical explanation sought for explaining collaborative advantage at one level is isomorphic with the explanation sought for explaining collaborative advantage at a different level. The explanatory (independent) variables likely differ, and the same variables may be causally related in different ways, depending on which level an explanation is sought. This means that there can be no unified theory of collaborative advantage; merely an ensemble of theoretical accounts of collaborative advantage at different analytical levels. Such incoherence is hardly desirable.

In fact, however, the extant literature on strategic alliances in management research, as well as basic notions from economics, allow us to go further and be more specific. Specifically, we propose the following components of a more precise understanding of collaborative advantage.

Advantage. We follow the strategic management literature and define "advantage" as a relative construct, namely the potential to create and capture more value than the relevant competition over some specified time-frame. From a theoretical perspective, one may assume that actors can be completely ordered on the basis of the extent to which they enjoy advantage.

Collaborative advantage (definition). Given the relative nature of advantage, collaborative advantage must imply that we are dealing with potential super-normal gains from trade; 
specifically, because of its collaborative activities a firm is capable of creating and capture more value than other meaningfully comparable firms. The latter category includes competitors within an industry (or a strategic group) as well as potential competitors (i.e., firms that are currently outside of the industry or the strategic group). The relevant potential super-normal gains from trade may stem from collaboration in the horizontal dimension, as when firms collaborate with competitors or complementors. Or, they may stem from collaboration in the vertical dimension, such as close relations to supplier firms or customers. These cases are obviously analytically different, and policy and strategy implications differ. However, space considerations prohibit a discussion of these issues. Suffice it to note that the relevant exchange that underlies collaborative advantage must go beyond ordinary spot-market exchange which is in principle open to any actor, and which, therefore, will not confer any advantage. Thus, collaborative advantage typically involves longer term relations between non-anonymous parties who participate in a venture where they pool complementary resources or the services of such resources in order to reach some shared goal. The paradigm example of this is the mutual conferment of specific investments to a relation, intensely studied in transaction cost economics (Williamson, 1996).

Locus of collaborative advantage. Given our association of advantage with (potential) appropriable value creation, we are dealing with actors who interact in markets, since appropriable value creation is only well-defined for such actors. This implies that we exclude collaboration between, for example, public utilities that do not interact on a market. We primarily associate collaborative advantage with firms, and locate such advantage at the firm level.

Often notions of advantage are transferred from the level of firms to higher level entities, such as regions (Storper, 1992) or even nations (e.g., Porter, 1990). The basic idea is that traded and untraded interdependencies (i.e., pecuniary and non-pecuniary externalities) may be geographically circumscribed, and accessible to "insiders" at significantly lower cost than to "outsiders" (Foss \& 
Eriksen, 1995). These interdependencies — which span multiple resource categories, such as abundant supply of advanced engineering services, trust relations, information flows, etc. —in effect become a kind of club goods (Buchanan, 1965). Writers often discuss industries, districts, regions, etc. characterized by such interdependencies as possessing advantage. While certain resources of a collaborative kind indeed arise in the interaction between firms, and as such in a certain sense lie outside of the boundaries of the firm (e.g., generalized trust relations in industry), the fact remains that firms are the loci of advantage, and of the value creation and appropriation that such advantage may give rise to. That this may benefit, for example, a region is obvious; however, the benefit emerges because the value creation that collaborative advantage may give rise to is appropriated by firms, and subsequently split between the multiple stakeholders of the relevant firms, many (most) of which are likely to be located in the region. We question whether it makes sense to say that the region as such can hold a collaborative advantage.

Antecedents of collaborative advantage. The antecedents of collaborative advantage include improved knowledge of the partner and of the opportunities that may be realized through collaboration (learning economies); and the building of trust; scale and scope advantages from the pooling of complementary resources etc. More generally, the ability to perform better in (subsequent) collaborations is typically conceived to be embedded in repetitive organizational activities that a firm develops in order to deploy its resources in collaborations (Helfat \& Peteraf, 2003). One may argue that, for example, "improved knowledge of the partner" is mainly located at the individual level, for example, in the memory of alliance managers, CEOs, etc. Thus, antecedents of collaborative advantage may, therefore, also exist at the level of individuals, in concert with strategic and structural levels (Knudsen \& Nielsen, 2010). Related, antecedents may exist at higher levels, for example, at the level of industries (Foss \& Eriksen, 1995). 
Scope conditions. As Suddaby (2010: 348) argues, in contrast to the "physical sciences, few constructs in organization theory have universal application." Indeed, much organizational theory is "middle-range theory" (Merton, 1968), that is, theory that only applies to a small set of phenomena/dependent variables, often only one. For example, research developed for the purpose of understanding certain aspects of a large, vertically integrated and publicly traded firms may not be relevant for understanding entrepreneurial upstart firms. ${ }^{3}$ In this case, the scope of theory is limited in the horizontal dimension because the theory applies to (the level of) firms, but only to a subset of firms.

Multilevel researchers argue that there is also a vertical dimension to the scope of a theory. Indeed, the notion of the "level of theory" refers to the focal unit or target at a given level (e.g., firm or dyad) that a researcher aims to explain, that is, "it is the level to which generalizations are made" (Rousseau, 1985: 4). The focal unit, in turn, determines the appropriate level associated with key constructs of interests. Typically, collaborative advantage is realized in small-numbers interaction (Williamson, 1985), such as joint ventures, strategic alliances, consortia or the like, and typically involve some specific and complementary assets. In these cases, the relevant levels of theory are those of the participating firms as well as the (dyadic) level of their collaborative activity.

As we suggested above, there are cases in which quite a large number of actors collaborate as a group and arguably hold advantages relative to outsiders because they participate in a network (region, industry, etc.) that goes significantly beyond the dyad. In such cases, it may be meaningful to consider an additional level of theory, namely the level of the network as a whole. Writers who argue that firms can benefit from participating in "clusters" (Porter, 1990) or "national systems of innovation" (Lundvall, 1992) or that industry membership provides access to specific "industry capabilities" (Foss \& Eriksen, 1995) implicitly or explicitly work with such a multi-layered

\footnotetext{
${ }^{3}$ This is not to say that there is no "grand theory" in organizational theory. Clearly, transaction cost economics aspires to this (Williamson, 1996).
} 
framework. Yet, only to the extent that the dependent variable is theorized at the network or cluster level (e.g., studies of how national systems of innovation or industry clusters compete with other similar types of networks) is the level of theory at this higher level. As we have indicated, we think there are reasons to be skeptical of claims that collaborative advantage itself is meaningfully placed at such levels; however, antecedents of collaborative advantage may well be located here.

Level of measurement refers to the actual source of the data, which should correspond to the level of constructs in order to increase the variability predicted by the theory. For instance, if the theory specifies within-group heterogeneity (e.g., in multi-level terminology, "alliances nested within firms", Nielsen, 2010), data collection should be conducted at the alliance level in order to ensure conformity with the theory and preserve the heterogeneity of the data within alliances. In such cases, collaborative advantage must by operationalized and measured as alliance-level advantages from collaborative efforts; for instance by focusing on the interactions between the partners to each specific alliance.

Finally, the level of analysis is concerned with the unit to which data are assigned and how data are treated during (statistical) analysis. The level of analysis must be aligned with the level of theory and measurement in order to appropriately assess the nested sources of variability. To the extent that collaborative advantage is theorized and measured as a firm-level construct that confers upon the holding firm some kind of advantage in (subsequent) interfirm dealings, the level of analysis should remain at the firm level as any aggregation or disaggregation runs the risk of influencing correlations and regression coefficients as well as potentially distorting the meaning of the data altogether.

\section{MULTILEVEL ISSUES, INTERFIRM RELATIONS, AND COLLABORATIVE ADVANTAGE}


Many discussions in the organizational literature lack attention to levels in general and microfoundations in particular (see Abell, Felin \& Foss, 2008; Dansereau, Yammarino \& Kohles, 1999; Felin \& Foss, 2005). Despite the growing use of collaborative alliances in a wide variety of settings, much of the organizational literature still focuses primarily on a single level of theorizing; typically the firm. The application of diverse theoretical approaches, such as resource dependence theory, microeconomics and strategic management, identify specific (industry or firm level) preconditions for collaboration and use these to predict organizational outcomes. However, they do so without regard to the underlying micro-foundational mechanisms which condition these outcomes.

Grounded in various theoretical perspectives and disciplines, such as transaction cost economics, social exchange theory, resource based view, evolutionary theory, industrial organization, and institutional theory, alliance research spans multiple levels (Nielsen, 2010). Yet many theories do not specify the mechanisms through which concepts at various levels are related, but are effectively mono-level theories (e.g., capabilities theories in strategic management) (Abell, Felin \& Foss, 2008). While some studies attempt to integrate theories, they typically do so without considering the level of conceptualization and generalization of these theories (e.g., Heimeriks, Duysters \& Vanhaverbeke, 2007; Lee \& Park, 2008). This often leads to mixing of constructs from different theoretical levels without the specification of cross-level relationships, and/or making predictions and testing propositions at a level that does not correspond to the underlying theory.

Multilevel theory development can help integrate such theories operating at different levels and specify the links between concepts from different levels of analysis that is multi-level theory explicates level-connecting mechanisms. In particular, interactions between factors at different levels offer potential avenues for advancing strategic alliance research and hold the potential for greatly improving theorizing about strategic alliance formation, dynamics and performance. Collaborative advantage, whether it is conceptualized as an antecedent variable in models of 
alliance (or firm) performance or acts as the dependent variable, constitutes one such concept which needs to be theorized, measured and analyzed through a multilevel lens.

Despite the pluralism of foundational theories invoked to examine collaborative interfirm relationships, explanations of collaborative advantage rests on a foundation of methodological individualism. Although most researchers would agree that collaborative advantage is inherently multilevel in nature, existing research primarily studies the phenomena at a single level of analysis (e.g., firm or dyad/alliance) with little attention to other effects at different levels of analysis, as well as potential cross-level effects. According to Dyer and Singh (2004), collaborating firms can generate relational rents, defined as “...a supernormal profit jointly generated in an exchange relationship that cannot be generated by either firm in isolation and can only be created through the joint idiosyncratic contributions of the specific alliance partners" (Dyer \& Singh, 2004: 351-352). Relational rents are determined by 1) the degree of investments in relation specific assets; 2) the degree of knowledge exchange; 3) the extent to which complementary, but scarce, resources or capabilities are combined; and 4) the extent of effective governance mechanisms (Dyer \& Singh, 2004). The main components of the rent-yielding factors are related to firm-level structural factors; for instance, contractual governance mechanisms. However, relational rents also refer to the importance of more intangible aspects of co-operation, such as trust, reputation and goodwill, as well as potentially to individual level skills and competences (Knudsen \& Nielsen, 2010). The existence of specific collaborative capabilities (resulting in a collaborative advantage) may help explain why some firms perform better than others when engaged in close collaboration activities as they "develop superior capabilities at managing particular organizational forms such as alliances" (Kale, Dyer \& Singh, 2002: 748). Yet, in order to adequately investigate the concept of collaborative advantage, a first step must be to clarify the concept in terms of level of theory and measurement. 


\section{Level of Theory and Measurement}

Multilevel theory rests on the ability of researchers to appropriately identify and define the focal units of a theory. When a focal unit of theoretical interest is identified, a multilevel theory can be developed and predictions can be made about how constructs at different levels are related to each other, and through which mechanisms (processes) (Hitt et al., 2007: 1388). Constructs are the building blocks of theory and the level of a construct is the level at which it is hypothesized to be manifest in a given model. Hence, it is paramount to define, justify and explain the level of each construct that constitutes a theoretical system.

Collaborative advantage raises immediate concerns regarding the appropriate level of theory as the above discussion illustrates; while some aspects of collaborative advantage rests on the firm's ability to develop and leverage (firm-level) organizational routines, which are repetitive activities that a firm develops in order to deploy its resources more effectively and efficiently in (subsequent) alliances (Helfat and Peteraf, 2003; Nelson and Winter, 1982), other aspects relate to (interfirmlevel) relational attributes, such as development of trust, goal congruency and relational embeddedness (Krishnan, Martin \& Noorderhaven, 2006; Nielsen, 2005). While the former studies draw on the resource-based view (RBV) and dynamic capabilities perspectives in arguing for firmlevel antecedents of collaborative capability, the literature on relational attributes of collaborative advantage, on the other hand, typically draws on social exchange theory, network theory or transaction cost economics to build theoretical arguments for the value-added of effective and efficient procedural and contractual governance of interfirm transactions. Moreover, individual skills and experiences may account for an essential part of the organizational memory and entail a set of repetitive activities ensuring a smooth and effective functioning of inter-organizational operations. The individual-level factors that contribute to collaborative advantage are thus related to the acquisition of new knowledge from external sources (Lane \& Lubatkin, 1998). The employees 
that are participating in collaborative activities where knowledge is sourced externally play an important role. This is emphasized in the work done on absorptive capacity where the role of 'gatekeepers' is pivotal. In their 1990 article, Cohen and Levinthal turned their attention towards the cognitive structures of the individuals of the organization and showed that in addition to being an organizational-level construct, absorptive capacity also exists at the individual level (Cohen \& Levinthal, 1990, p.132).

No single theory or paradigm is likely to provide an adequate foundation for a general theory explaining the antecedents and outcomes of collaborative advantage. For instance, while application of transaction cost economics (TCE) may be appropriate for studying the establishment and structuring of alliances, managerial processes leading to alliance outcomes may be better assessed by drawing on social exchange or learning theories. In addition, the applicability of each theory may depend on situation specific factors; for instance, the resource based view (RBV) may be more suitable to the study of collaborative advantage in dynamic industries, whereas institutional theory may be more relevant for collaborative advantage in international alliances than for purely domestic ones. As a result, explicit integration of theories that span different levels holds great potential for facilitating new theory generation and empirical developments in collaborative advanage research. A starting point for such theory generation is to clarify the focal unit of interest and the resulting role of collaborative advantage in the theoretical system.

Nesting of collaborative advantage. The central theme of multilevel thinking is that organizational entities reside in nested arrangements and that more complete models of organizational phenomena must account for this nested structure both theoretically and empirically in order to advance organizational research (House, Rousseau \& Thomas-Hunt, 1995). The structure is (typically) hierarchically nested so that higher-level units encompass those at lower 
levels. The importance of identifying nested structures lies in the fact that observations within higher level units are more similar than across those units. Because lower level units share common features and influences from the higher level units, they are not independent from each other. For instance, there is variability between firms within alliances but also between alliances in terms of performance. Whereas certain alliances perform better than others, individual firms within each alliance may also experience different performance consequences. Neglecting to account for such nesting may lead to wrong conclusions if either of these sources of variability is ignored during (statistical) analysis. For example, multiple alliances formed by a firm can share some governance, management and performance practices. Similarly, multiple alliances located in a particular country (e.g., China) may have the same governance form due to idiosyncratic institutional characteristics of that country. Most empirical research does not account for the nested structure of the data and typically either simply controls for higher-level factors (e.g., industry or environmental effects) or treat them as same-level, independent variables. However, such treatment may lead to misspecifications and erroneous interpretations of results due, for example, to violation of the independence assumption underlying most regression models.

In research on strategic alliances, the focal unit of interest is typically either the alliance or the firm. For instance, research on alliance formation is preoccupied with identifying the factors determining the propensity to form alliances or the governance structure of the alliance. The focal unit in the former is the firm as researchers seek to explain the variability in firm's propensity to form alliances, whereas in the latter the focal unit and the dependent variables are specified at the level of the alliance. Essentially, it is the dependent variable(s) of a particular study that determines the level of theory. Studies typically focus on a single alliance per firm or consider each alliance in isolation without accounting for the interdependence of alliances as part of a portfolio. Yet, managing a portfolio of alliances is likely to create value beyond what can be accomplished if each 
alliance were managed separately (Heimeriks et al., 2007). Such additional value stems from homogeneity in the processes utilized to coordinate knowledge across the portfolio of alliances (Dyer \& Hatch, 2006). To the extent that multiple alliances managed by a firm share some features, similar alliance processes (management practices) are likely to influence subsequent performance. Thus, it is necessary to account for this similarity between alliances within firms by explicitly modeling the nesting. At the same time, it is important to recognize that significant differences exist between multiple alliances managed by a firm and this heterogeneity needs to be modeled and explained as well. In terms of level of theory, measurement and analysis, this implies that a distinction must be made between constructs at each level (e.g., firm versus alliance) in order to model the variance at both alliance and firm level as well as the potential relationships across levels.

As discussed earlier, collaborative advantage is made up by, at least, firm and interfirm level antecedents (as well as potentially individual level micro-foundational predictors and network, industry or country level macro-foundational influences) and is itself an antecedent to firm or alliance level performance. Depending on the focal unit of theory the theoretical building blocks of collaborative advantage may differ. For instance, if a study is preoccupied with explaining variability in firm-level performance as a function of a firm's collaborative advantage, the role of collaborative advantage is at the portfolio level and the researcher must consequently conceptualize and measure collaborative advantage as a function of the firm's ability to manage synergies across multiple alliances. Alternatively, studies that seek to explain how collaborative advantage contributes to alliance performance (for instance measured as JV performance or number of patents resulting from a particular alliance) must focus on firm-level attributes contributed by both (all) firms in the alliance. At the same time, a number of other variables at different levels may potentially influence the relationship between collaborative advantage and performance and the nature of such cross-level interactions is also likely to vary with the level of theory. For example, 
while industry competitive rivalry may exert positive influence on the collaborative advantageperformance relationship at the firm level, such interaction is less likely to be theoretically justifiable when the unit of theory is the alliance portfolio. Specification of such multilevel models may be accomplished in several ways and we now turn to a discussion of such specifications.

\section{Specifying Multilevel Collaborative Advantage Models}

To the extent that phenomena at one level impact those at another, cross-level theories may be more appropriate than single-level theories. One type of cross-level theoretical model specifies antecedent predictor variables and dependent outcome variables at different levels. In terms of modeling collaborative advantage, this may imply either conceptualizing various lower (or higher) level influences on the development of collaborative advantage or treating collaborative advantage as an antecedent variable of higher level outcomes. For instance, to the extent that collaborative advantage is conceived as a firm-level phenomenon (i.e. a firms ability to extract superior rents from it capability to manage collaborative relationships), a multilevel theoretical model may be specified where individual (e.g., alliance manager or gate-keeper), team (e.g., alliance team), firm (e.g., investment in alliance resources such as an alliance unit), and perhaps industry (e.g., technological change, industry structure or profitability) characteristics determine the amount of collaborative advantage. By the same token, if treated as an antecedent variable, multilevel models may specify how various measures of collaborative advantage influence firm or alliance performance.

A second type of cross-level model is found in studies which include contextual factors as moderators of interfirm relationships. For instance, industry (e.g. dynamism or growth) and/or macro-environmental factors (e.g., country risk, protectionist legislation or environmental uncertainty) may moderate relationships between various antecedent variables and collaborative advantage or between collaborative advantage and performance. Appropriate specification (both 
theoretically and empirically) of moderator variables at multiple levels may yield novel insights into the conditions under which certain established relationships hold or change. Indeed, such multilevel contingency models could be extended to include multiple factors at various levels simultaneously in order to bring alliance research closer to the complexity of alliance practice. While rare in extant literature, moderator variables from levels below the relationships they moderate are possible and may further advance the understanding of collaborative advantage. For instance, specific characteristics (e.g., demographic or psychological) of individual alliance managers or top management teams may influence the relation between antecedent variables and collaborative advantage or between collaborative advantage and various outcome variables, such as firm- or alliance performance.

A particular type of multi-level models is concerned with patterns of relationships that can be replicated across levels of analysis. Such models describe relationships at one level that are generalizable to other levels - that is constructs and their relations are presumed to be meaningful across levels. In interfirm research, few such constructs have been specified, though a number of constructs are often treated (implicitly) as if they have such generalizable properties (e.g., trust). Collaborative advantage is a particularly ambiguous construct in terms of levels of theory and analysis and not specifying clearly how it translates from the organization to the interfirm relationship and beyond may blur the theoretical development and empirical analyses. As pointed out earlier, certain aspects of collaborative advantage may reside within the organizational boundaries, whereas others may be a function of relational interaction with alliance partners or indeed industry structure and competition. While the underlying assumption is that collaborative advantage characteristics are similar across analytical levels, very few studies specify and measure the extent to which the processes leading to firm-level collaborative advantage mirror those that lead to interfirm collaborative advantage, thereby increasing the risk of committing a "cross-level 
fallacy" (Rousseau, 1985). For instance, according to the resource-based view (RBV), firms are bundles of resources and competitive advantage is achieved by the effective management of internal resources (Barney, 1991). Since resources are heterogeneously distributed across firms, this perspective recognizes that some important internal resources can be obtained from external sources via alliances; however, by and large such theories neglect to stipulate the mechanisms by which firm level resources can affect and be affected by exchange between complex social systems, such as organizations. Such mechanisms are likely to influence the extent to which collaborative advantage, conceptualized and measured at the firm level, can be generalized to higher/lower levels.

\section{CONCLUDING DISCUSSION}

We began this chapter by noting the vague and unclear status of the notion of collaborative advantage. However, as is often the case with fuzzy concepts in social science, collaborative advantage captures relevant and important phenomena. Accordingly, we set out to proffer a clarification of the construct, attempting to define the meaning of collaborative advantage as an inherently and inescapably multilevel phenomenon, whose potential value rests on the theoretical and methodological clarity and rigor of researchers applying it. If an elusive and ambiguous construct such as collaborative advantage is to become useful in management and social science research, there is a great need to adequately define its theoretical borders; the scope conditions; semantic relationships to other related constructs; and the logical consistency of argumentation (Suddaby, 2010). Given the multilevel nature of collaborative advantage, levels of theory, measurement and analysis must be aligned in order to ensure construct clarity and avoid model misspecifications and empirical misinterpretations. Specifically, careful attention must be paid to the level of theory from which multilevel constructs, such as collaborative advantage, belong and determine to what extent relationships among variables generalize across levels before data is collected and subjected to statistical analysis. Hence, we contend that future research on 
collaborative advantage must start by addressing the fundamental issues of defining and clarifying the construct in terms of levels of theory, measurement and analysis outlined in this chapter.

This is particularly pertinent, given a certain amount of "levels confusion" in the literature: Presumably because of its general and intuitive appeal (i.e., any advantage to any actor that arises because of collaboration), collaborative advantage has been treated as an unproblematic construct that can be applied almost at will at any level of analysis (from the level of collaborating individuals to collaborating nations). We have criticized this, suggesting that in much research collaborative advantage is applied to levels where it may not make conceptual/logical sense. For example, we have questioned whether it makes sense to ascribe collaborative advantage to e.g., a national system of innovation. More fundamentally, this suggests that, extreme care should be taken when applying constructs developed for one level of theory to another one. Not only may constructs not be applicable to any level of theory, the underlying causal mechanisms may differ when traversing levels.

In spite of a long history of recognizing that organizational phenomena unfold within complex and dynamic systems, management research and organizational science often ignores the multilevel dynamics of these social systems. The system is typically divided into industry, alliance, organization, team, and individual level subparts, each part the providence of different disciplines, theories, perspectives and approaches. As a result, coherent research on organizational phenomena as integrated systems spanning multiple levels of theory, measurement and analysis are scarce, constituting a critical omission in the progression of organizational and management science.

This chapter has outlined important multilevel issues pertaining to research on collaborative advantage. Our aim was to highlight fundamental issues of construct clarity in relation to collaborative advantage. In this regard, we highlighted on the issues of specification of levels of theory, measurement and analysis. Our chapter has brought to focus the importance of adequately 
defining the meaning of collaborative advantage construct as well as illustrated the profound implications of adequately specifying the nested structure of the collaborative advantage phenomenon. Multilevel research-research examining the extent and correlates of variability in both antecedents and consequences of collaborative advantage at multiple levels-holds great promise for advancing this area of research. Thus, although we have issued a series of methodological warnings and have offered a mild criticism of what we see as a tendency to indiscriminately transfer constructs (and claims about causal mechanisms) about levels of theory/analysis, the other side of the coin is that multi-level research on collaborative advantage offers significant potential for interesting future research questions. In particular, the attention of researchers is directed to potentially novel explanatory mechanisms and independent variables at different levels. For example, in the context of alliance research, it may be quite useful to consider variables typically addressed in the national innovation systems literature, such as specific national policies and institutional arrangements. Such variables must be theoretically specified (in the sense of accounting for their moderating, mediating, or direct impact on collaborative advantage) and empirically modeled (in the sense that level of measurement matches level of analysis).

As we close this chapter, we issue a final warning regarding future research on collaborative advantage; despite its intuitive appeal, collaborative advantage must be better grounded theoretically in order to realize its potential as an informative social science construct. Such theoretical grounding may start with construct clarification, however, should move beyond pure descriptive properties of what collaborative advantage is to include considerations of how (the relationship to other constructs), when (the contextual conditions), and why (the causal mechanisms) (Bacharach, 1989) collaborative advantage matters. Indeed, we suggest that multilevel theorizing may be a vehicle to help clarify the boundaries, contingencies and interdependent nature of collaborative advantage and move research forward. 


\section{REFERENCES}

Abell, P., T. Felin \& N.J. Foss. 2008. Building micro-foundations for the routines, capabilities, and performance links. Managerial and Decision Economics, 29(6): 489-502.

Anand, B., \& T. Khanna. 2000. Do firms learn to create value? The case of alliances. Strategic Management Journal, 21(3), 295-315.

Axelsson, B. \& G. Easton, eds. 1992. Industrial Networks: A New View of Reality. London: Routledge.

Bacharach, S.B. 1989. Organizational theories: some criteria for evaluation, Academy of Management Review, 14: 496-515.

Barney, J.B. 1991. Firm resources and sustained competitive advantage. Journal of Management, 17: 99-121.

Buchanan, J. 1965. An economic theory of clubs. Economic Journal, 32: 1-14.

Cohen, W. \& D. Levinthal. 1990. Absorptive capacity: a new perspective of learning and innovation, Administrative Science Quarterly, 35: 128-152.

Dansereau, F., F. J. Yammarino and J. C. Kohles. 1999. Multiple Levels of Analysis from a Longitudinal Perspective: Some Implications for Theory Building. Academy of Management Review, 24: 346-357

Dyer, J. 2000. Collaborative Advantage: Winning Through Extended Enterprise Supplier Networks. Oxford: Oxford University Press.

Dyer, J. H., \& N.W. Hatch. 2006. Relation-specific capabilities and barriers to knowledge transfers: Creating advantage through network relationships. Strategic Management Journal, 27(8), 701719.

Dyer, J. H. \& H. Singh. 2004. The Relational View: Cooperative Strategy and Sources of Interorganizational Competitive Advantage, in Jeffrey J. Reuer (Ed) Strategic Alliances. Theory and Evidence. Oxford: Oxford University Press.

Felin, T. \& N.J. Foss. 2005. Strategic Organization: a field in search of micro-foundations. Strategic Organization, 3: 441-455.

Foss, N.J. \& B. Eriksen. 1995. Industry Capabilities and Competitive Advantage, in C.A. Montgomery, ed. 1995.Evolutionary and Resource-Based Approaches to Strategy. Boston: Kluwer.

Heimeriks, K., G.M. Duysters \& W. Vanhaverbeke. 2007. Learning mechanisms and differential performance effects in alliance portfolios. Strategic Organization, 5(4), 373-408. 
Helfat, C.E. \& M.A. Peteraf. (2003) The dynamic resource-based view: capability lifecycles. Strategic Management Journal. Vol. 24, No. 10, pp. 997-1010.

Hirschman, A.O. 1970. Exit, Voice, and Loyalty: Responses to Decline in Firms, Organizations, and States. Cambridge, MA: Harvard University Press.

Hitt, M., P.W. Beamish, S.E. Jackson. \& J.E. Mathieu. 2007. Building theoretical and empirical bridges across levels: Multilevel research in management. Academy of Management Journal, 50(6), 1385-1399.

House, R., D.M. Rousseau. \& M. Thomas-Hunt. 1995. The meso paradigm: A framework for the integration of micro and macro organizational behavior. Research in Organizational Behavior, 17, 71-114.

Huxham, C., ed. 1996. Creating Collaborative Advantage. London: Sage.

Huxham, C. and S. Vangen. 2005. Managing to Collaborate: The Theory and Practice of Collaborative Advantage. London: Routledge.

Kale, P., J.H. Dyer \& H. Singh. 2002. Alliance capability, stock market response, and long-term alliance success: The role of the alliance function. Strategic Management Journal, 23(8), 747-767.

Kanter, R.M. 1994. Collaborative Advantage: The Art of Alliances. Harvard Business Review (July-August): 96-108.

Klein, K. J., F. Dansereau \& R.J. Hall. 1994. Levels issues in theory development, data collection, and analysis. Academy of Management Review, 19(2), 195-229.

Knudsen, L. \& B.B. Nielsen. 2010. Collaborative capability in R\&D alliances: exploring the link between organisational- and individual-level factors. International Journal of Knowledge Management Studies, 4(2): 152-175.

Krishnan, R., X. Martin \& N. Noorderhaven. 2006. When does trust matter to alliance performance? Academy of Management Journal, 49(5), 894-917.

Lane, P.J. \& M. Lubatkin. 1998. Relative absorptive capacity and interorganizational learning, Strategic Management Journal, 19: 461-477.

Lank, E. 2005. Collaborative Advantage: How Organizations Win by Working Together. London: Palgrave MacMillan.

Lazzarini, S., G. Miller \& T. Zenger. 2004. Order with some law: Complementarity versus substitution of formal and informal arrangements. Journal of Law, Economics, and Organization, 20: 261- 298.

Lee, H.-U., \& J.H. Park. 2008. The influence of top management team international exposure on international alliance formation. Journal of Management Studies, 45(5): 961-981. 
Merton, R. K. 1968. Social Theory and Social Structure. New York: Free Press

Nelson, R. R., \& S.G. Winter. 1982. An evolutionary theory of economic change. Cambridge, MA: Harvard University Press.

Nielsen, B.B. 2005. The role of knowledge embeddedness in the creation of synergies in strategic alliances. Journal of Business Research, 58(9): 1194-1204.

Nielsen, B.B. 2010. Multilevel issues in alliance research. Forthcoming in Researching Strategic Alliances: Emerging Perspectives, T.K. Das (Editor). New York: Information Age Publishing.

Peteraf, M. \& J.B. Barney. 2003. Unravelling the resource-based tangle. Managerial and Decision Economics, 24: 309-324.

Porter, M.E. 1990. The Competitive Advantage of Nations. New York: Free Press.

Richardson, G.B. 1972. The Organisation of ndustry. Economic Journal 82: 883-896.

Rousseau, D.M. 1985. Issues of level on organizational research: Multi-level and cross-level perspectives. Research in Organizational Behavior, 7, 1-37.

Saxonian, A. 1991. The Origin and Dynamics of Production Networks in Silicon Valley. Research Policy, 20: 423-437.

Storper, M. 1992.The Limits to Globalization: Technology Districts and International Trade. Economic Geography, 68: 60-93.

Suddaby, R. 2010. Construct Clarity in Theories in Management and Organization. Academy of Management Review, 35: 346-357. 


\section{SMG - Working Papers \\ www.cbs.dk/smg \\ 2003}

2003-1: Nicolai J. Foss, Kenneth Husted, Snejina Michailova, and Torben Pedersen: Governing Knowledge Processes: Theoretical Foundations and Research Opportunities.

2003-2: Yves Doz, Nicolai J. Foss, Stefanie Lenway, Marjorie Lyles, Silvia Massini, Thomas P. Murtha and Torben Pedersen: Future Frontiers in International Management Research: Innovation, Knowledge Creation, and Change in Multinational Companies.

2003-3: Snejina Michailova and Kate Hutchings: The Impact of In-Groups and OutGroups on Knowledge Sharing in Russia and China CKG Working Paper.

2003-4: Nicolai J. Foss and Torben Pedersen: The MNC as a Knowledge Structure: The Roles of Knowledge Sources and Organizational Instruments in MNC Knowledge Management CKG Working Paper.

2003-5: Kirsten Foss, Nicolai J. Foss and Xosé H. Vázquez-Vicente: “Tying the Manager's Hands": How Firms Can Make Credible Commitments That Make Opportunistic Managerial Intervention Less Likely CKG Working Paper.

2003-6: Marjorie Lyles, Torben Pedersen and Bent Petersen: Knowledge Gaps: The Case of Knowledge about Foreign Entry.

2003-7: Kirsten Foss and Nicolai J. Foss: The Limits to Designed Orders: Authority under "Distributed Knowledge" CKG Working Paper.

2003-8: Jens Gammelgaard and Torben Pedersen: Internal versus External Knowledge Sourcing of Subsidiaries - An Organizational Trade-Off.

2003-9: Kate Hutchings and Snejina Michailova: Facilitating Knowledge Sharing in Russian and Chinese Subsidiaries: The Importance of Groups and Personal Networks Accepted for publication in Journal of Knowledge Management.

2003-10: Volker Mahnke, Torben Pedersen and Markus Verzin: The Impact of Knowledge Management on MNC Subsidiary Performance: the Role of Absorptive Capacity CKG Working Paper.

2003-11: Tomas Hellström and Kenneth Husted: Mapping Knowledge and Intellectual Capital in Academic Environments: A Focus Group Study Accepted for publication in Journal of Intellectual Capital CKG Working Paper.

2003-12: Nicolai J Foss: Cognition and Motivation in the Theory of the Firm: Interaction or "Never the Twain Shall Meet"? Accepted for publication in Journal des Economistes et des Etudes Humaines CKG Working Paper.

2003-13: Dana Minbaeva and Snejina Michailova: Knowledge Transfer and Expatriation Practices in MNCs: The Role of Disseminative Capacity.

2003-14: Christian Vintergaard and Kenneth Husted: Enhancing Selective Capacity Through Venture Bases. 


\section{4}

2004-1: Nicolai J. Foss: Knowledge and Organization in the Theory of the Multinational Corporation: Some Foundational Issues

2004-2: Dana B. Minbaeva: HRM Practices and MNC Knowledge Transfer

2004-3: Bo Bernhard Nielsen and Snejina Michailova: Toward a Phase-Model of Global Knowledge Management Systems in Multinational Corporations

2004-4: Kirsten Foss \& Nicolai J Foss: The Next Step in the Evolution of the RBV: Integration with Transaction Cost Economics

2004-5: Teppo Felin \& Nicolai J. Foss: Methodological Individualism and the Organizational Capabilities Approach

2004-6: Jens Gammelgaard, Kenneth Husted, Snejina Michailova: Knowledge-sharing Behavior and Post-acquisition Integration Failure

2004-7: Jens Gammelgaard: Multinational Exploration of Acquired R\&D Activities

2004-8: Christoph Dörrenbächer \& Jens Gammelgaard: Subsidiary Upgrading? Strategic Inertia in the Development of German-owned Subsidiaries in Hungary

2004-9: Kirsten Foss \& Nicolai J. Foss: Resources and Transaction Costs: How the Economics of Property Rights Furthers the Resource-based View

2004-10: Jens Gammelgaard \& Thomas Ritter: The Knowledge Retrieval Matrix: Codification and Personification as Separate Strategies

2004-11: Nicolai J. Foss \& Peter G. Klein: Entrepreneurship and the Economic Theory of the Firm: Any Gains from Trade?

2004-12: Akshey Gupta \& Snejina Michailova: Knowledge Sharing in Knowledge-Intensive Firms: Opportunities and Limitations of Knowledge Codification

2004-13: Snejina Michailova \& Kate Hutchings: Knowledge Sharing and National Culture: A Comparison Between China and Russia

\section{5}

2005-1: Keld Laursen \& Ammon Salter: My Precious - The Role of Appropriability Strategies in Shaping Innovative Performance

2005-2: Nicolai J. Foss \& Peter G. Klein: The Theory of the Firm and Its Critics: A Stocktaking and Assessment

2005-3: Lars Bo Jeppesen \& Lars Frederiksen: Why Firm-Established User Communities Work for Innovation: The Personal Attributes of Innovative Users in the Case of Computer-Controlled Music

2005-4: Dana B. Minbaeva: Negative Impact of HRM Complementarity on Knowledge Transfer in MNCs

2005-5: Kirsten Foss, Nicolai J. Foss, Peter G. Klein \& Sandra K. Klein: Austrian Capital 
Theory and the Link Between Entrepreneurship and the Theory of the Firm

2005-1: Nicolai J. Foss: The Knowledge Governance Approach

2005-2: Torben J. Andersen: Capital Structure, Environmental Dynamism, Innovation Strategy, and Strategic Risk Management

2005-3: Torben J. Andersen: A Strategic Risk Management Framework for Multinational Enterprise

2005-4: Peter Holdt Christensen: Facilitating Knowledge Sharing: A Conceptual Framework

2005-5 Kirsten Foss \& Nicolai J. Foss: Hands Off! How Organizational Design Can Make Delegation Credible

2005-6 Marjorie A. Lyles, Torben Pedersen \& Bent Petersen: Closing the Knowledge Gap in Foreign Markets - A Learning Perspective

2005-7 Christian Geisler Asmussen, Torben Pedersen \& Bent Petersen: How do we Capture "Global Specialization" when Measuring Firms' Degree of internationalization?

2005-8 Kirsten Foss \& Nicolai J. Foss: Simon on Problem-Solving: Implications for New Organizational Forms

2005-9 Birgitte Grøgaard, Carmine Gioia \& Gabriel R.G. Benito: An Empirical Investigation of the Role of Industry Factors in the Internationalization Patterns of Firms

2005-10 Torben J. Andersen: The Performance and Risk Management Implications of Multinationality: An Industry Perspective

2005-11 Nicolai J. Foss: The Scientific Progress in Strategic Management: The case of the Resource-based view

2005-12 Koen H. Heimeriks: Alliance Capability as a Mediator Between Experience and Alliance Performance: An Empirical Investigation Into the Alliance Capability Development Process

2005-13 Koen H. Heimeriks, Geert Duysters \& Wim Vanhaverbeke: Developing Alliance Capabilities: An Empirical Study

2005-14 JC Spender: Management, Rational or Creative? A Knowledge-Based Discussion

\section{6}

2006-1: Nicolai J. Foss \& Peter G. Klein: The Emergence of the Modern Theory of the Firm

2006-2: Teppo Felin \& Nicolai J. Foss: Individuals and Organizations: Thoughts on a Micro-Foundations Project for Strategic Management and Organizational Analysis

2006-3: Volker Mahnke, Torben Pedersen \& Markus Venzin: Does Knowledge Sharing 
Pay? An MNC Subsidiary Perspective on Knowledge Outflows

2006-4: Torben Pedersen: Determining Factors of Subsidiary Development

2006-5 Ibuki Ishikawa: The Source of Competitive Advantage and Entrepreneurial Judgment in the RBV: Insights from the Austrian School Perspective

2006-6 Nicolai J. Foss \& Ibuki Ishikawa: Towards a Dynamic Resource-Based View: Insights from Austrian Capital and Entrepreneurship Theory

2006-7 Kirsten Foss \& Nicolai J. Foss: Entrepreneurship, Transaction Costs, and Resource Attributes

2006-8 Kirsten Foss, Nicolai J. Foss \& Peter G. Klein: Original and Derived Judgement: An Entrepreneurial Theory of Economic Organization

2006-9 Mia Reinholt: No More Polarization, Please! Towards a More Nuanced Perspective on Motivation in Organizations

2006-10 Angelika Lindstrand, Sara Melen \& Emilia Rovira: Turning social capital into business? A study of Swedish biotech firms' international expansion

2006-11 Christian Geisler Asmussen, Torben Pedersen \& Charles Dhanaraj: Evolution of Subsidiary Competences: Extending the Diamond Network Model

2006-12 John Holt, William R. Purcell, Sidney J. Gray \& Torben Pedersen: Decision Factors Influencing MNEs Regional Headquarters Location Selection Strategies

2006-13 Peter Maskell, Torben Pedersen, Bent Petersen \& Jens Dick-Nielsen: Learning Paths to Offshore Outsourcing - From Cost Reduction to Knowledge Seeking

2006-14 Christian Geisler Asmussen: Local, Regional or Global? Quantifying MNC Geographic Scope

2006-15 Christian Bjørnskov \& Nicolai J. Foss: Economic Freedom and Entrepreneurial Activity: Some Cross-Country Evidence

2006-16 Nicolai J. Foss \& Giampaolo Garzarelli: Institutions as Knowledge Capital: Ludwig M. Lachmann's Interpretative Institutionalism

2006-17 Koen H. Heimriks \& Jeffrey J. Reuer: How to Build Alliance Capabilities

2006-18 Nicolai J. Foss, Peter G. Klein, Yasemin Y. Kor \& Joseph T. Mahoney: Entrepreneurship, Subjectivism, and the Resource - Based View: Towards a New Synthesis

2006-19 Steven Globerman \& Bo B. Nielsen: Equity Versus Non-Equity International Strategic Alliances: The Role of Host Country Governance

\section{7}

2007-1 Peter Abell, Teppo Felin \& Nicolai J. Foss: Building Micro-Foundations for the Routines, Capabilities, and Performance Links 
2007-2 Michael W. Hansen, Torben Pedersen \& Bent Petersen: MNC Strategies and Linkage Effects in Developing Countries

2007-3 Niron Hashai, Christian G. Asmussen, Gabriel R.G. Benito \& Bent Petersen: Predicting the Diversity of Foreign Entry Modes

2007-4 Peter D. Ørberg Jensen \& Torben Pedersen: Whether and What to Offshore?

2007-5 Ram Mudambi \& Torben Pedersen: Agency Theory and Resource Dependency Theory: Complementary Explanations for Subsidiary Power in Multinational Corporations

2007-6 Nicolai J. Foss: Strategic Belief Management

2007-7 Nicolai J. Foss: Theory of Science Perspectives on Strategic Management Research: Debates and a Novel View

2007-8 Dana B. Minbaeva: HRM Practices and Knowledge Transfer in MNCs

2007-9 Nicolai J. Foss: Knowledge Governance in a Dynamic Global Context: The Center for Strategic Management and Globalization at the Copenhagen Business School

2007-10 Paola Gritti \& Nicolai J. Foss: Customer Satisfaction and Competencies: An Econometric Study of an Italian Bank

2007-11 Nicolai J. Foss \& Peter G. Klein: Organizational Governance

2007-12 Torben Juul Andersen \& Bo Bernhard Nielsen: The Effective Ambidextrous Organization: A Model of Integrative Strategy Making Processes.

\section{8}

2008-1 Kirsten Foss \& Nicolai J. Foss: Managerial Authority When Knowledge is Distributed: A Knowledge Governance Perspective

2008-2 Nicolai J. Foss: Human Capital and Transaction Cost Economics.

2008-3 Nicolai J. Foss \& Peter G. Klein: Entrepreneurship and Heterogeneous Capital.

2008-4 Nicolai J. Foss \& Peter G. Klein: The Need for an Entrepreneurial Theory of the Firm.

2008-5 Nicolai J. Foss \& Peter G. Klein: Entrepreneurship: From Opportunity Discovery to Judgment.

2008-6 Mie Harder: How do Rewards and Management Styles Influence the Motivation to Share Knowledge?

2008-7 Bent Petersen, Lawrence S. Welch \& Gabriel R.G. Benito: Managing the Internalisation Process - A Theoretical Perspective.

2008-8 Torben Juul Andersen: Multinational Performance and Risk Management Effects: Capital Structure Contingencies. 
2008-9 Bo Bernard Nielsen: Strategic Fit and the Role of Contractual and Procedural Governance in Alliances: A Dynamic Perspective.

2008-10 Line Gry Knudsen \& Bo Bernhard Nielsen: Collaborative Capability in R\&D Alliances: Exploring the Link between Organizational and Individual level Factors.

2008-11 Torben Juul Andersen \& Mahesh P. Joshi: Strategic Orientations of Internationalizing Firms: A Comparative Analysis of Firms Operating in Technology Intensive and Common Goods Industries.

2008-12 Dana Minbaeva: HRM Practices Affecting Extrinsic and Intrinsic Motivation of Knowledge Receivers and their Effect on Intra-MNC Knowledge Transfer.

2008-13 Steen E. Navrbjerg \& Dana Minbaeva: HRM and IR in Multinational Corporations: Uneasy Bedfellows?

2008-14 Kirsten Foss \& Nicolai J. Foss: Hayekian Knowledge Problems in Organizational Theory.

2008-15 Torben Juul Andersen: Multinational Performance Relationships and Industry Context.

2008-16 Larissa Rabbiosi: The Impact of Subsidiary Autonomy on MNE Knowledge Transfer: Resolving the Debate.

2008-17 Line Gry Knudsen \& Bo Bernhard Nielsen: Organizational and Individual Level Antecedents of Procedural Governance in Knowledge Sharing Alliances.

2008-18 Kirsten Foss \& Nicolai J. Foss: Understanding Opportunity Discovery and Sustainable Advantage: The Role of Transaction Costs and Property Rights.

2008-19 Teppo Felin \& Nicolai J. Foss: Social Reality, The Boundaries of Self-fulfilling Prophecy, and Economics.

2008-20 Yves Dos, Nicolai J. Foss \& José Santos: A Knowledge System Approach to the Multinational Company: Conceptual Grounding and Implications for Research

2008-21 Sabina Nielsen \& Bo Bernhard Nielsen: Why do Firms Employ foreigners on Their Top Management Teams? A Multi-Level Exploration of Individual and Firm Level Antecedents

2008-22 Nicolai J. Foss: Review of Anders Christian Hansen's “Uden for hovedstrømmen - Alternative strømninger i økonomisk teori"

2008-23 Nicolai J. Foss: Knowledge, Economic Organization, and Property Rights

2008-24 Sjoerd Beugelsdijk, Torben Pedersen \& Bent Petersen: Is There a Trend Towards Global Value Chain Specialization? - An Examination of Cross Border Sales of US Foreign Affiliates 
2008-25 Vikas Kumar, Torben Pedersen \& Alessandro Zattoni: The performance of business group firms during institutional transition: A longtitudinal study of Indian firms

2008-26 Sabina Nielsen \& Bo B. Nielsen: The effects of TMT and Board Nationality Diversity and Compensation on Firm Performance

2008-27 Bo B. Nielsen \& Sabina Nielsen: International Diversification Strategy and Firm Performance: A Multi-Level Analysis of Firm and Home Country Effects

\section{9}

2009-1 Nicolai J. Foss: Alternative Research Strategies in the Knowledge Movement: From Macro Bias to Micro-Foundations and Multi-Level Explanation

2009-2 Nicolai J. Foss \& Peter G. Klein: Entrepreneurial Alertness and Opportunity Discovery: Origins, Attributes, Critique

2009-3 Nicolai J. Foss \& Dana B. Minbaeva: Governing Knowledge: The Strategic Human Resource Management Dimension

2009-4 Nils Stieglitz \& Nicolai J. Foss: Opportunities and New Business Models: Transaction Cost and Property Rights Perspectives on Entrepreneurships

2009-5 Torben Pedersen: Vestas Wind Systems A/S: Exploiting Global R\&D Synergies

2009-6 Rajshree Agarwal, Jay B. Barney, Nicolai J. Foss \& Peter G. Klein: Heterogeneous Resources and the Financial Crisis: Implications of Strategic Management Theory

2009-7 Jasper J. Hotho: A Measure of Comparative Institutional Distance

2009-8 Bo B. Nielsen \& Sabina Nielsen: The Impact of Top Management Team Nationality Diversity and International Experience on Foreign Entry Mode

2009-9 Teppo Felin \& Nicolai Juul Foss: Experience and Repetition as Antecedents of Organizational Routines and Capabilities: A Critique of Behaviorist and Empiricist Approaches

2009-10 Henk W. Volberda, Nicolai J. Foss \& Marjorie E. Lyles: Absorbing the Concept of Absorptive Capacity: How To Realize Its Potential in the Organization Field

2009-11 Jan Stentoft Arlbjørn, Brian Vejrum Wæhrens, John Johansen \& Torben Pedersen: Produktion i Danmark eller offshoring/outsourcing: Ledelsesmæssige udfordringer 


\section{0}

2010-1 Dana B. Minbaeva, Kristiina Mäkelä \& Larissa Rabbiosi: Explaining Intraorganizational Knowledge Transfer at the Individual Level

2010-2 Dana B.Minbaeva \& Torben Pedersen: Governing Individual Knowledge Sharing Behavior

2010-3 Nicolai J. Foss \& Peter G. Klein: Alertness, Judgment, and the Antecedents of Entrepreneurship

2010-4 Nicolai J.Foss \& Joseph T.Mahoney: Exploring Knowledge Governance

2010-5 Jasper J. Hotho, Florian Becker-Ritterspach \& Ayse Saka-Helmhout: Enriching Absorptive Capacity Through Social Interaction

2010-6 Nicolai J. Foss \& Bo B. Nielsen: Researching Collaborative Advantage: Some Conceptual and Multi-level Issues 